\title{
Development and use of a polarized equine upper respiratory tract mucosal explant system to study the early phase of pathogenesis of a European strain of equine arteritis virus
}

\author{
Sabrina Vairo ${ }^{1}$, Wim Van den Broeck ${ }^{2}$, Herman Favoreel $^{3}$, Alessandra Scagliarini $^{4}$ and Hans Nauwynck ${ }^{1 *}$
}

\begin{abstract}
The upper respiratory tract mucosa represents the first line of defense, which has to be overcome by pathogens before invading the host. Considering the economic and ethical aspects involved in using experimental animals for pathogenesis studies, respiratory mucosal explants, in which the tissue's three-dimensional architecture is preserved, may be ideal alternatives. Different respiratory mucosal explant cultures have been developed. However, none of them could be inoculated with pathogens solely at the epithelium side. In the present study, equine nasal and nasopharyngeal explants were embedded in agarose (3\%), leaving the epithelium side exposed to allow apical inoculation. Morphometric analysis did not show degenerative changes during $72 \mathrm{~h}$ of cultivation. The number of apoptotic cells in the mucosa slightly increased over time. After validation, the system was used for apical infection with a European strain (08P178) of equine arteritis virus (EAV) $\left(10^{7.6} \mathrm{TCID}_{50} / \mathrm{mL}\right.$ per explant). Impermeability of agarose to virus particles was demonstrated by the absence of labeled microspheres (40nm) and a lack of EAV-antigens in RK13 cells seeded underneath the agarose layer in which inoculated explants were embedded. At 72 hpi, 27\% of the EAV-positive cells were CD172a ${ }^{+}$and $19 \%$ were $\mathrm{CD}^{+}$in nasal explants and $45 \%$ of the EAV-positive cells were CD172a ${ }^{+}$and $15 \%$ were $\mathrm{CD}^{+}$in nasopharyngeal explants. Only a small percentage of EAV-positive cells were $\operatorname{lgM}^{+}$. This study validates the usefulness of a polarized mucosal explant system and shows that $\mathrm{CD} 172 \mathrm{a}^{+}$myeloid cells and $\mathrm{CD}^{+}{ }^{+} \mathrm{T}$ lymphocytes represent important EAV-target cells in the respiratory mucosa.
\end{abstract}

\section{Introduction}

The respiratory mucosa consists of the epithelium and the underlying connective tissue or lamina propria that are separated by a firm barrier, the basement membrane (BM). It lines the respiratory tract, including the nasal cavity, the nasopharynx, the larynx, the trachea and the bronchial tree and represents the first line of defense against respiratory infections. However, several pathogens, including equine arteritis virus (EAV) [1], use the respiratory tract as a portal of entry to invade the host. At the level of the respiratory mucosa, the mechanisms of replication and invasion of many of these pathogens

\footnotetext{
* Correspondence: hans.nauwynck@ugent.be

'Laboratory of Virology, Department of Virology, Parasitology and Immunology, Faculty of Veterinary Medicine, Ghent University, Merelbeke B-9820, Belgium

Full list of author information is available at the end of the article
}

are largely unknown. In vivo experiments are difficult to perform due to their costs and ethical constraints. Recently, Glorieux et al., Vandekerckhove et al., and Steukers et al. developed ex vivo explant models using gauzes to cultivate respiratory mucosae of pigs [2], horses [3] and cattle [4], respectively. These models were successfully used to get better insight into the invasion mechanisms of alphaherpesviruses [5]. However, the impossibility to inoculate the mucosa solely at the epithelial side was a limitation. In fact, inoculation of equine explants cultivated on gauzes with pseudorabies virus (PRV) resulted in infection of endothelial cells while the epithelium above them was unaffected [6]. Therefore, the author concluded that infection occurred via the side regions of the explants [6]. In line with this, when equine explants cultivated on gauzes are experimentally 
infected with a European EAV strain (08P178), the majority of infected cells are localized in the connective tissue mainly at the bottom and lateral sides of the explants. In an in vivo situation, viruses have to overcome the epithelial layer before invading the host. In the explant system using only gauzes, all sides of the mucosal explants become exposed to the virus and this barrier phenomenon is, therefore, lost. As a consequence, early pathogenic events of certain respiratory agents, such as EAV, may be quite different in these ex vivo models compared to those in the in vivo situation. Therefore, it was necessary to create a model where the virus could only be delivered at the apical side. The present study describes a polarized agarose embedded explant model which allows cultivation of equine nasal and nasopharyngeal mucosae in a semiclosed system where only the epithelium side of the explant is exposed to virus upon inoculation. Agarose is a linear galactose polymer obtained by purification of agar [7] and it is frequently used as an alternative to agar in viral plaque assays [8] and microbiological investigations [9]. In the present study, agarose embedded respiratory mucosal explants were tested for morphometric integrity and cell viability. Additionally, this polarized ex vivo model was used to investigate EAV replication sites and to identify the mucosal target cells.

\section{Material and methods}

Collection of nasal and nasopharyngeal mucosae and preparation of agarose embedded explant cultures

Nasal septum, nasopharynx and blood from seven horses of both genders and different ages (3-6 years old) were collected at the slaughterhouse as previously described [3]. The collected tissues were immediately transported to the laboratory in transport medium: phosphate buffered saline (PBS) supplemented with $10 \mu \mathrm{g} / \mathrm{mL}$ gentamicin (Invitrogen, Ghent, Belgium), $1 \mathrm{mg} / \mathrm{mL}$ streptomycin (Certa, Braine l'Alleud, Belgium), $1 \mathrm{mg} / \mathrm{mL}$ kanamycin (Sigma, Bornem, Belgium), 1000U/mL penicillin (Continental Pharma, Puurs, Belgium) and $5 \mu \mathrm{g} / \mathrm{mL}$ fungizone (Bristol-Myers Squibb, New York, USA). The mucosae were stripped from the underlying layers and divided into equal fractions of $2 \mathrm{~cm}^{2}$. The nasal explants were cultured on gauzes for $24 \mathrm{~h}$ in 50\% D-MEM (Invitrogen)/50\% F12 (Invitrogen) serum-free medium supplemented with $1 \mu \mathrm{g} / \mathrm{mL}$ gentamicin, $0.1 \mathrm{mg} / \mathrm{mL}$ streptomycin and $100 \mathrm{U} / \mathrm{mL}$ penicillin. The nasopharyngeal explants were cultured on gauzes for $24 \mathrm{~h}$ in $50 \%$ D-MEM/50\% RPMI (Invitrogen) serum-free medium supplemented with $1 \mathrm{nM} \mathrm{Ca}{ }^{++}, 1 \mu \mathrm{g} / \mathrm{mL}$ gentamicin, 0.1 $\mathrm{mg} / \mathrm{mL}$ streptomycin and $100 \mathrm{U} / \mathrm{mL}$ penicillin.

Six-well culture dishes were pre-seeded with rabbit kidney cells (RK13) and incubated at $37^{\circ} \mathrm{C}$ in the presence of $5 \% \mathrm{CO}_{2}$ until confluency was reached. Afterwards, RK13 medium was replaced with $3 \mathrm{~mL}$ of a solution containing
$50 \%$ of sterile 3\% agarose (low temperature gelling; Sigma) and $50 \%$ of $2 \mathrm{X}$ medium $(50 \% 2 \mathrm{X}$ D-MEM/50\% $2 \mathrm{X}$ F12 supplemented with $2 \mu \mathrm{g} / \mathrm{mL}$ gentamicin, $0.2 \mathrm{mg} / \mathrm{mL}$ streptomycin and $200 \mathrm{U} / \mathrm{mL}$ penicillin for nasal explants; $50 \%$ 2X D-MEM/50\% 2X RPMI supplemented with 2nM $\mathrm{Ca}^{++}, 2 \mu \mathrm{g} / \mathrm{mL}$ gentamicin, $0.2 \mathrm{mg} / \mathrm{mL}$ streptomycin and $200 \mathrm{U} / \mathrm{mL}$ penicillin for nasopharyngeal explants). Once the agarose layer solidified, $1.5 \mathrm{~cm}^{2}$ of stripped mucosa was placed on top of it with the epithelium upwards. Additional agarose was added until the lateral surfaces of the mucosa were fully occluded. Finally, to avoid drying out during incubation $\left(37^{\circ} \mathrm{C}\right.$ and $\left.5 \% \mathrm{CO}_{2}\right)$, the nasal and nasopharyngeal mucosae were covered with a tiny film of nasal or nasopharyngeal serum-free medium, respectively. Nasal and nasopharyngeal mucosae collected from three horses were used to examine the structural integrity and viability of the agarose embedded explants. Upper respiratory mucosae of the remaining four animals were included to investigate the replication and to identify the target cells of EAV $08 P 178$ in the agarose embedded explants. To exclude previous EAV infection of the donor animals, blood samples collected at the slaughterhouse were tested for EAV specific antibodies by means of a complementdependent virus neutralization (VN) test and an immunoperoxidase monolayer assay (IPMA) as previously described [1]. Further, to exclude recent EAV infection, $20 \%$ suspensions of nasal and nasopharyngeal mucosae were processed for virus titration on RK13 cells, immediately after collection at the slaughterhouse.

\section{Morphometric analysis}

At $0,24,48$ and $72 \mathrm{~h}$ of cultivation, nasal and nasopharyngeal explants were fixed in phosphate buffered 3.5\% formaldehyde solution for $24 \mathrm{~h}$. After fixation, the tissues were further processed with an automated system (Shandon Citadel Tissue Processor, 420 D) and embedded in paraffin. Afterwards, haematoxylin-eosin (HE), reticulin and Van Gieson stainings were performed. At each time point, the effect of ex vivo cultivation on the mucosa architecture was evaluated in five randomly selected fields. The structure and thickness of the epithelium were analyzed in the HE stained sections. The thickness and the continuity of the basement membrane were evaluated in the reticulin stained sections. The relative amounts of collagen and nuclei were calculated in a defined region of interest from five randomly chosen fields in the Van Gieson stained sections. All measurements and calculations were performed using the Cell F Software linked to a BX61 light microscope (Olympus Optical Co., Hamburg, Germany).

\section{Evaluation of cell viability}

The effect of ex vivo cultivation on cell viability was evaluated using an in-situ cell death detection kit (Roche 
Diagnostics Corporation, Basel, Switzerland), based on terminal deoxynucleotidyl transferase mediated dUTP nick end labeling (TUNEL). The TUNEL test was performed according to the manufacturer's guidelines on cryosections preserved in methocel ${ }^{\circledR}$ (Sigma). In both epithelium and connective tissues, the percentage of TUNEL-positive cells was assessed in five randomly chosen fields of 100 cells each.

\section{Validation of the impermeability of agarose to virus particles}

To confirm the agarose impermeability to virus particles, a preliminary experiment with fluorescent microspheres was performed. Briefly, a dual-chamber system was created by placing a transwell insert (pore size $0.4 \mu \mathrm{m}, 12$ $\mathrm{mm}$ of diameter; Millipore corporation, Bedford, MA, USA) filled with $3 \mathrm{~mL}$ of $50 \%$ agarose (3\%) and $50 \% 2 \mathrm{X}$ medium into a culture dish of a six-well plate. Three $\mathrm{mL}$ of PBS were added to the bottom compartment. One $\mathrm{mL}$ of PBS containing $10^{7.6}$ streptavidin-labeled microspheres (40nm) (Invitrogen) with slightly smaller dimensions compared to EAV particles (50-100nm) [10] was brought to the upper compartment, on top of the agarose layer. Zero, 1, 12, 48, 72 and $96 \mathrm{~h}$ later, $50 \mu \mathrm{L}$ of fluid was collected from both the upper and the bottom compartments and analyzed with a fluoroskan ascent FL (Thermo lab system, Altrincham, GB, UK).

To verify that the virus did not cross the agarose layer during the experimental inoculation, wells used to culture agarose embedded EAV-inoculated explants were pre-seeded with RK13 cells. After collection of the explants, the agarose layer was gently removed from the wells and the underlying RK13 monolayer was washed, air dried and submitted for indirect immunohistochemistry (IHC). Briefly, the monolayers were fixed with $4 \%$ paraformaldehyde for $10 \mathrm{~min}$ at room temperature, washed twice with PBS and further incubated with methanol supplemented with $0.1 \% \mathrm{H}_{2} \mathrm{O}_{2}$. The monolayers were subsequently incubated for $1 \mathrm{~h}$ with mouse monoclonal antibody (mAb) 17D3 (1:100), specific for the nucleocapsid (N) protein of EAV (VMRD, Pullman, USA) and with a peroxidase-labeled goat anti-mouse IgG immunoglobulin (Molecular Probes, Oregon, USA) (1:500). Viral antigen-positive RK13 cells were visualized with $0.05 \mathrm{M}$ of 3-amino-9-ethylcarbazole in acetate buffer (pH5) supplemented with $0.05 \% \mathrm{H}_{2} \mathrm{O}_{2}$ and detected by light microscopy (Olympus Optical Co.).

\section{Virus inoculation}

After validation of the agarose embedded explant system, the model was used to investigate EAV replication and to identify the target cells. Nasal and nasopharyngeal agarose embedded mucosal explants of three horses were inoculated with $1 \mathrm{~mL}$ of medium containing $10^{7.6}$
$50 \%$ endpoint tissue culture infectious dose $\left(\mathrm{TCID}_{50}\right)$ of a European respiratory strain of EAV (isolated in Belgium, designated $08 P 178,4^{\text {th }}$ passage on RK13 cells) [GenBank: JN25761], [1]. The agarose embedded explants of a fourth animal were mock-inoculated with 1 $\mathrm{mL}$ of medium. After $1 \mathrm{~h}$ of incubation at $37^{\circ} \mathrm{C}$ and $5 \%$ $\mathrm{CO}_{2}$, the inoculum was removed, the explants were gently washed twice and further incubated with fresh medium. At 0, 24, 48 and $72 \mathrm{hpi}$, specimens were collected for quantification and identification of EAV infected cells by double immunofluorescence stainings (IF).

\section{Identification of EAV infected cells}

To quantify and identify individual EAV-positive cells, a double immunofluorescence staining was performed. For each donor animal and at each collection time, sixty 8 $\mu \mathrm{m}$-thick cryosections of nasal mucosa and sixty $8 \mu \mathrm{m}$ thick cryosections of nasopharyngeal mucosa were cut and fixed in methanol at $-20^{\circ} \mathrm{C}$ for $20 \mathrm{~min}$. For each tissue, twenty cryosections were stained for each cell surface marker separately. In the first step, optimal dilutions of mAb DH59B (VMRD), UC F6G-3 (California University, Davis, USA) or 1.9/3.2 (VMRD) were used as markers

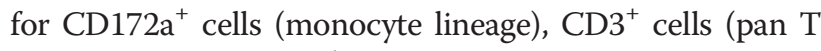
lymphocytes) and $\operatorname{IgM}^{+}$cells (B lymphocytes), respectively. Afterwards, slides were incubated with Texas $\operatorname{Red}^{\circledR}$ labeled goat anti-mouse IgG antibodies (Molecular Probes). In the second step, EAV nucleocapsid (N) protein was visualized with mAb 17D3 (VMRD), directly labeled with Zenon ${ }^{\circledR}$ Alexa Fluor ${ }^{\circledR} 488$ Mouse IgG1 Labeling Kit, according to the manufacturer's instructions. As a negative control, sections of the mock-inoculated nasal mucosa were stained following the aforementioned protocol. In addition, ten extra sections of inoculated nasal mucosa were incubated with $\mathrm{CD} 172 \mathrm{a}^{+}$as primary antibody and Texas $\operatorname{Red}^{\circledR}$-labeled goat anti-mouse IgG antibodies as secondary antibody. In a second step, the glass was further incubated with an irrelevant IgG1 directly labeled with Zenon $^{\circledR}$ Alexa Fluor ${ }^{\circledR} 488$ Mouse IgG1 Labeling Kit. All antibodies were diluted in PBS and incubated for $1 \mathrm{~h}$ at $37^{\circ} \mathrm{C}$. The nuclei were counterstained with Hoechst 33342 (Molecular Probes) for $10 \mathrm{~min}$ followed by a further fixation step of 5 min with $4 \%$ paraformaldehyde. The number of viral-antigen positive cells was determined in an area of $8 \mathrm{~mm}^{2}$ for each nasal and nasopharyngeal mucosae. Further, at each time point, the percentage of double positive cells (EAV-surface marker ${ }^{+}$) was calculated on the total amount of EAV-positive cells counted in the 20 sections stained for that specific cell marker. The samples were analyzed with a confocal microscope (Leica TCS SP2 Laser scanning spectral confocal system, Leica microsystems GmbH, Wetzlar, Germany). 


\section{Statistical analysis}

Morphometric parameters and viability were analyzed using Prism software to evaluate the variance (ANOVA). The data are presented as means \pm standard deviation of triple independent experiments. The results were considered to be significantly different when $p<0.05$.

\section{Results}

\section{Morphometry}

In both nasal and nasopharyngeal mucosal explants, the architecture of the epithelium (Figure 1a), and the continuity of the basement membrane (Figure 2a) were preserved throughout the entire experiment. The thickness of the epithelium and the basement membrane did not significantly change over time (Figures $1 \mathrm{~b}$ and $2 \mathrm{~b}$, respectively).

In both nasal and nasopharyngeal mucosae, the relative amounts of nuclei (Figures 3a, 3b) and collagen (Figures $3 \mathrm{a}$ and $3 \mathrm{c}$ ) were conserved over time.

\section{Viability}

The effect of ex vivo culture on explant viability is given in Table 1. The nasal and nasopharyngeal mucosal explants show a slight, not statistically significant, increase in the number of apoptotic epithelial and stromal cells at $72 \mathrm{~h}$ of cultivation.

\section{Ability of agarose to restrain virus particles}

The bead assay, as specified in the material and methods, indicates the ability of agarose to restrain virus particles. None of the samples collected from the bottom compartment of the dual-chamber system contain- ed streptavidin-labeled microspheres at any time point. Microspheres remained present in the fluid collected from the upper compartment up to $96 \mathrm{hpi}$. In the absence of agarose, microspheres were readily observed in the lower compartment.

In addition, IHC staining performed on the RK13 monolayer seeded underneath the EAV-inoculated agarose embedded explants did not reveal EAV-positive cells at any time point.

\section{Quantification and identification of EAV-antigen positive cells in agarose embedded explants}

Samples included as negative control did not show EAV-positive cells at any time point. The number of EAV-positive cells increased in time with a mean of 68 in $8 \mathrm{~mm}^{2}$ of nasal mucosa and 225 in $8 \mathrm{~mm}^{2}$ of nasopharyngeal mucosa at $72 \mathrm{hpi}$. In particular, 54, 74 and 76 antigen-positive cells $/ 8 \mathrm{~mm}^{2}$ were counted in nasal explants (Figure 4a) and 201, 220 and 254 EAV-positive cells $/ 8 \mathrm{~mm}^{2}$ were quantified in nasopharyngeal explants (Figure 4b) of horse 1, 2 and 3, respectively. Specifically, in nasal mucosa, 22, 34 and $27 \%$ of EAV-positive cells were identified as $\mathrm{CD}_{172 \mathrm{a}^{+}}$at 24,48 and $72 \mathrm{hpi}$, respectively. The percentage of EAV infected cells positive for CD3 increased linearly from 10 (24 hpi) to 19\% (48 and $72 \mathrm{hpi}$ ) during the experiment (Figure 5a). In the nasopharyngeal mucosal explants, the percentage of EAV infected cells positive for CD172a increased from 22 (24 hpi) to 26 (48 hpi) and $45 \%$ (72 hpi) over time, while the percentage of EAV infected CD3 cells reached $22 \%$ at $24 \mathrm{hpi}$ and decreased to $15 \%$ afterwards (48 and 72 hpi) (Figure 5b). At $24 \mathrm{hpi}$, EAV-positive cells were

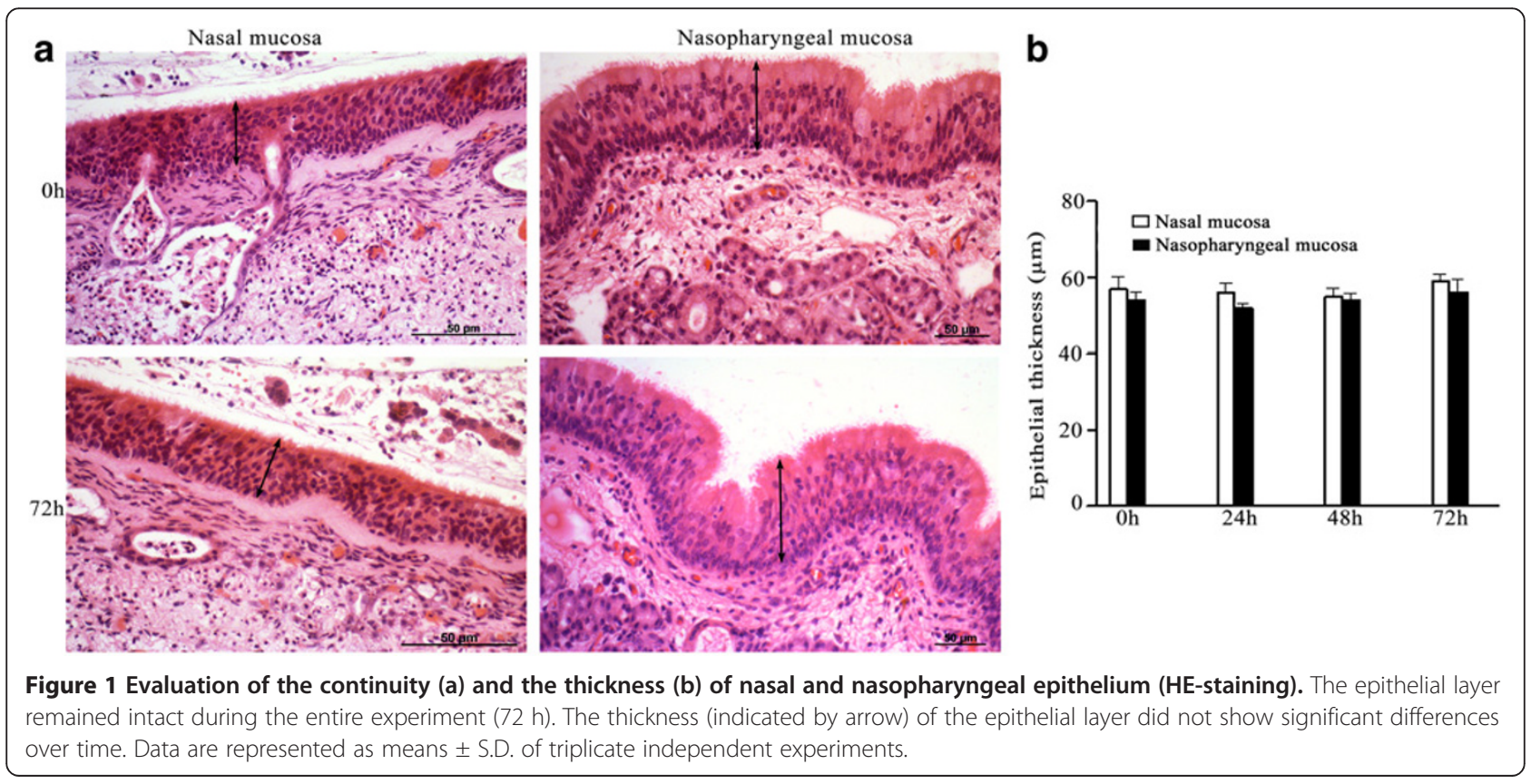




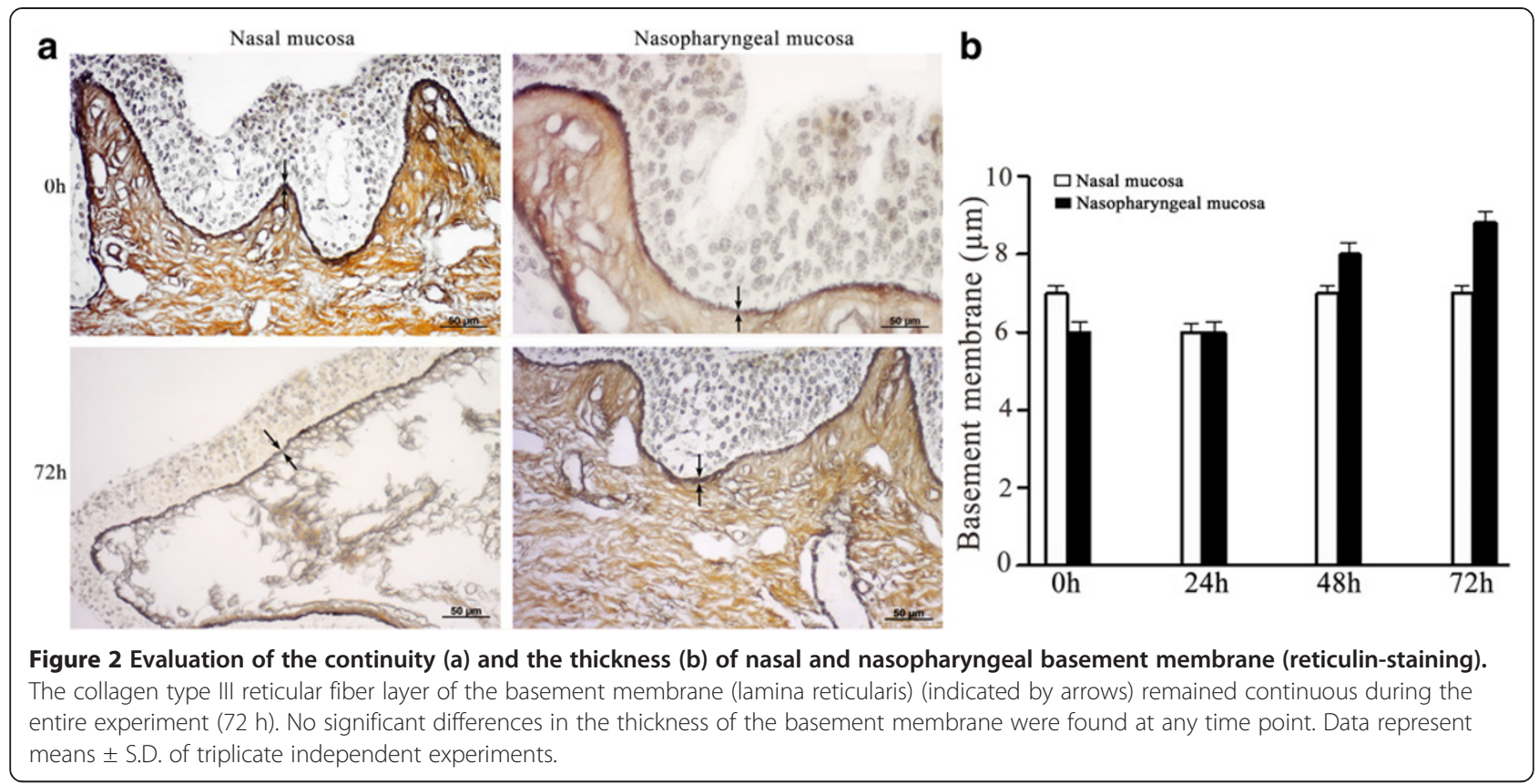

mainly localized in the upper layers of both nasal and nasopharyngeal mucosae and, at later time points (48 and $72 \mathrm{hpi}$ ), were scattered all over the connective tissue. In general, individual EAV-infected cells were mostly found under the basement membrane with a sporadic presence in between epithelial cells. In addition, in nasopharyngeal explants individual EAV- positive cells were frequently localized in the parafollicular area. Viral antigen-positive cells were not found at the cutting edges of the agarose embedded explants. Intracellularly, viral antigens were seen in the cytoplasm (Figure 6), in the form of small dots (Figure 6a) but mostly in the form of large masses occupying most of the cytoplasm (Figures $6 \mathrm{~b}$ and $\mathrm{c}$ ).

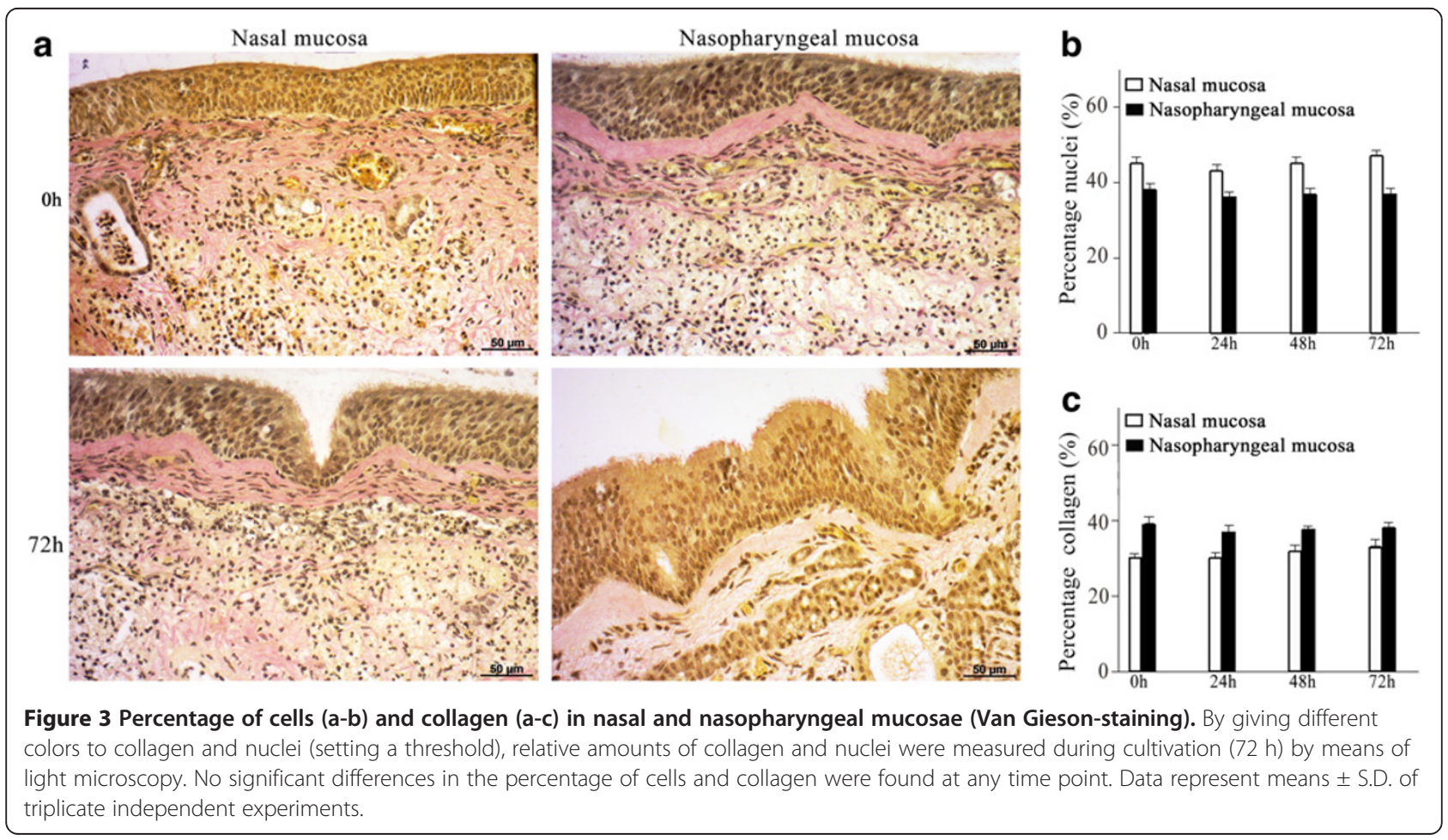


Table 1 Percentage of TUNEL-positive cells in the epithelium and underlying connective tissue.

\begin{tabular}{|c|c|c|c|c|c|}
\hline & \multicolumn{5}{|c|}{ Percentage of TUNEL-positive cells at. . .h of cultivation } \\
\hline & & 0 & 24 & 48 & 72 \\
\hline \multirow[t]{2}{*}{ Nasal mucosa } & epithelium & $0.2 \pm 0.4$ & $0.6 \pm 0.6$ & $0.4 \pm 0.2$ & $0.4 \pm 0.8$ \\
\hline & lamina propria & $0.8 \pm 0.7$ & $1.3 \pm 1.0$ & $3.0 \pm 0.7$ & $4.9 \pm 2.7$ \\
\hline \multirow[t]{2}{*}{ Nasopharyngeal mucosa } & epithelium & $0.4 \pm 0.3$ & $0.8 \pm 1.0$ & $0.7 \pm 1.3$ & $0.7 \pm 0.5$ \\
\hline & lamina propria & $0.5 \pm 0.8$ & $1.7 \pm 1.8$ & $3.0 \pm 0.4$ & $5.5 \pm 1.9$ \\
\hline
\end{tabular}

Percentage of TUNEL-positive cells was used as a parameter to determine the effect of in vitro culture on the viability of equine nasal and nasopharyngeal agarose embedded mucosal explants. No significant differences in the occurrence of apoptosis were found at any time point. Data are represented as means $\pm \mathrm{S}$. D. of triplicate independent experiments.

\section{Discussion}

The mucosa of the upper respiratory tract (URT) represents the first line of defense against respiratory pathogens but often also serves as a portal of entry for several microorganisms, whether or not causing generalized infection. The principal viral agents responsible for respiratory disorders in horses are equine herpesvirus-1 (EHV-1) and equine herpesvirus-4 (EHV-4) [11], equine arteritis virus (EAV) [12] and equine influenza virus [13]. A previous system used by Vandekerckhove et al. allowed cultivating four representative tissues of the equine URT up to $96 \mathrm{~h}$ without significant changes in morphology and viability [3]. In that model, the explants were cultivated on gauzes allowing nutrients to penetrate through all sides of the mucosa. Because of the small size of the explants $\left(0.5 \mathrm{~cm}^{2}\right.$, few $\mathrm{mm}$ thick $)$ and

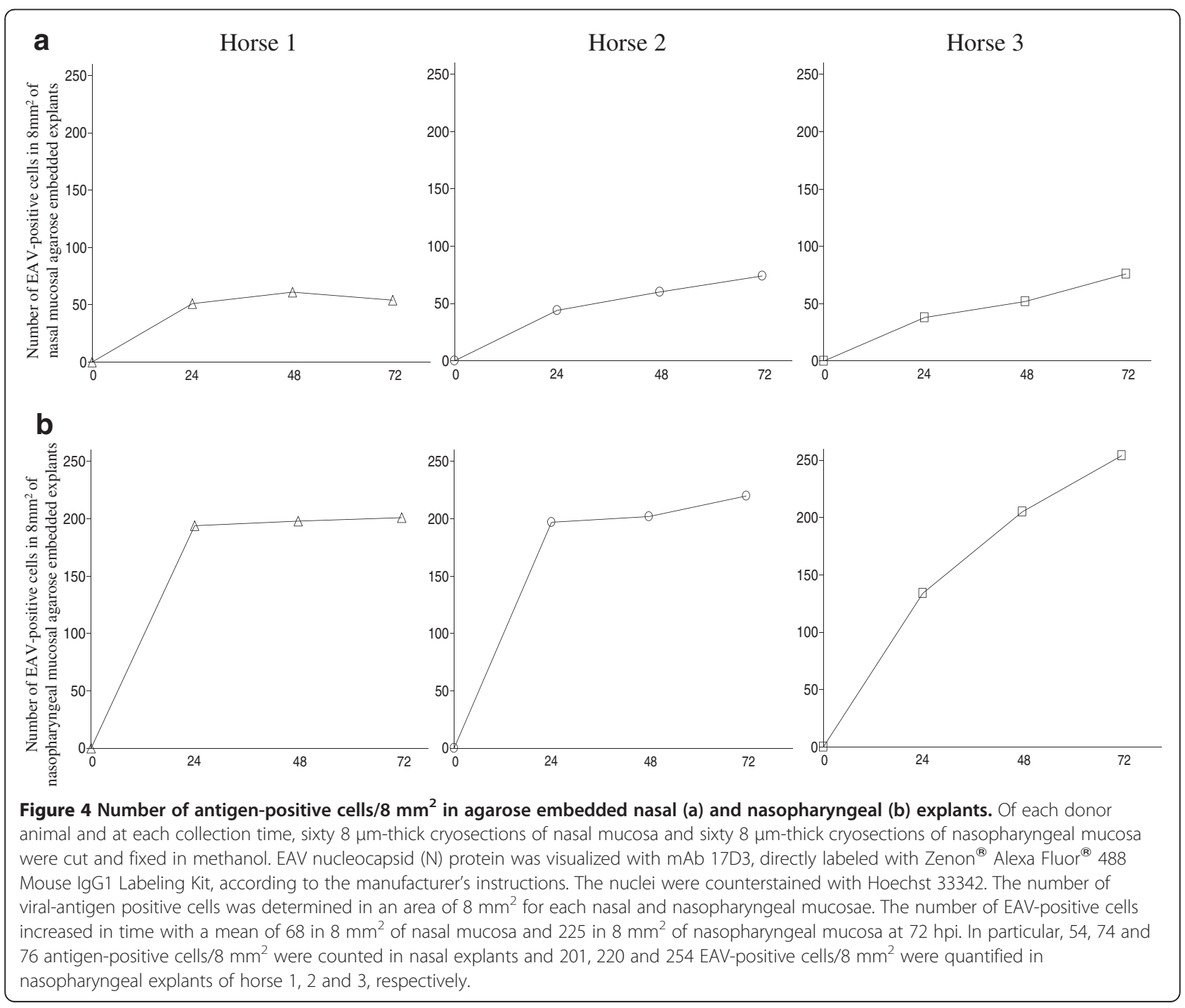



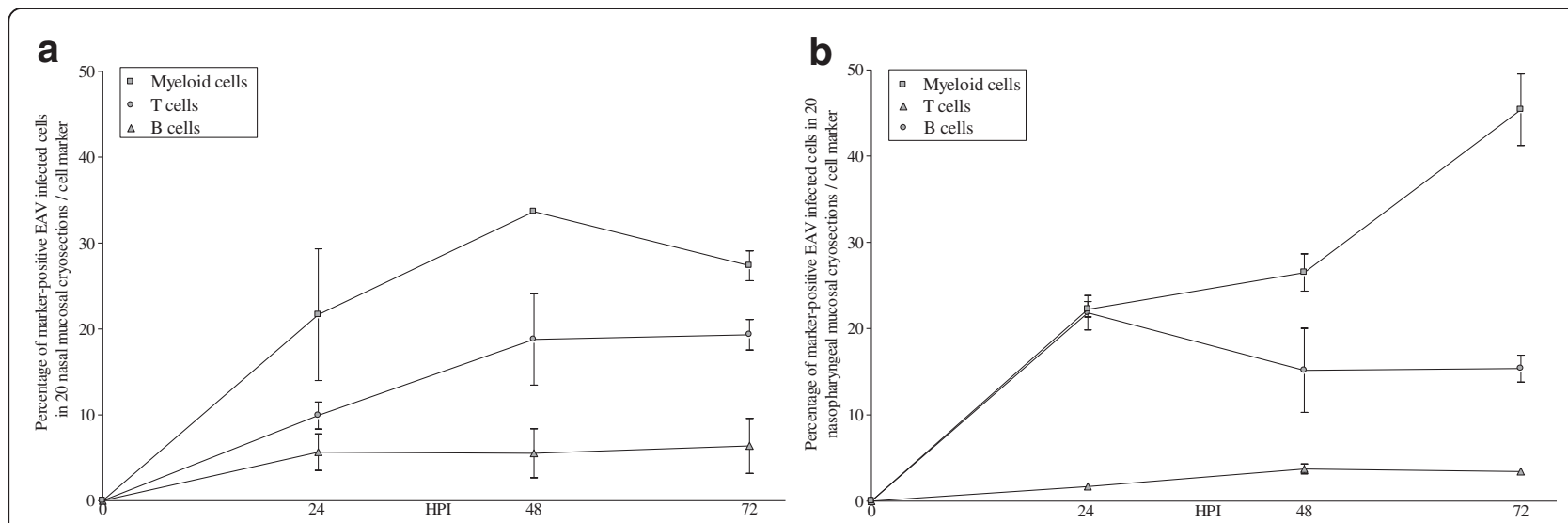

Figure 5 Identification of EAV-positive leukocytes in agarose embedded nasal (a) and nasopharyngeal (b) explants. Lines show the means \pm S.D. of triplicate independent experiments.

the open edges, nutrients have free access to the inner parts of the tissues. In this system, pathogens, just like nutrients, do not only enter the mucosa at the upper epithelium side, but also at the edges through the open spaces of the connective tissue. In fact, inoculation of such explant systems with PRV [6] or EAV 08P178 (our own studies, not published) resulted in an extensive spread of the virus, mainly at the bottom and lateral sides of the mucosal explants. Therefore, in order to better mimic the in vivo situation, we established a new model in which, through agarose embedded explants, a polarized system was obtained so that pathogens could only enter through the upper epithelium. The results of morphometric analysis of the epithelium, basement membrane and connective tissue and of TUNEL assays demonstrate that the agarose system allows cultivating explants up to $72 \mathrm{~h}$ without substantial alterations in the morphology and the viability of the tissues. Further, an assay based on streptavidin-labeled microspheres together with the absence of EAV-antigens in RK13 cells seeded underneath the agarose layer in which inoculated explants were embedded and the lack of viral antigenpositive cells at the cutting edges of the agarose embedded explants, demonstrate that the access of the

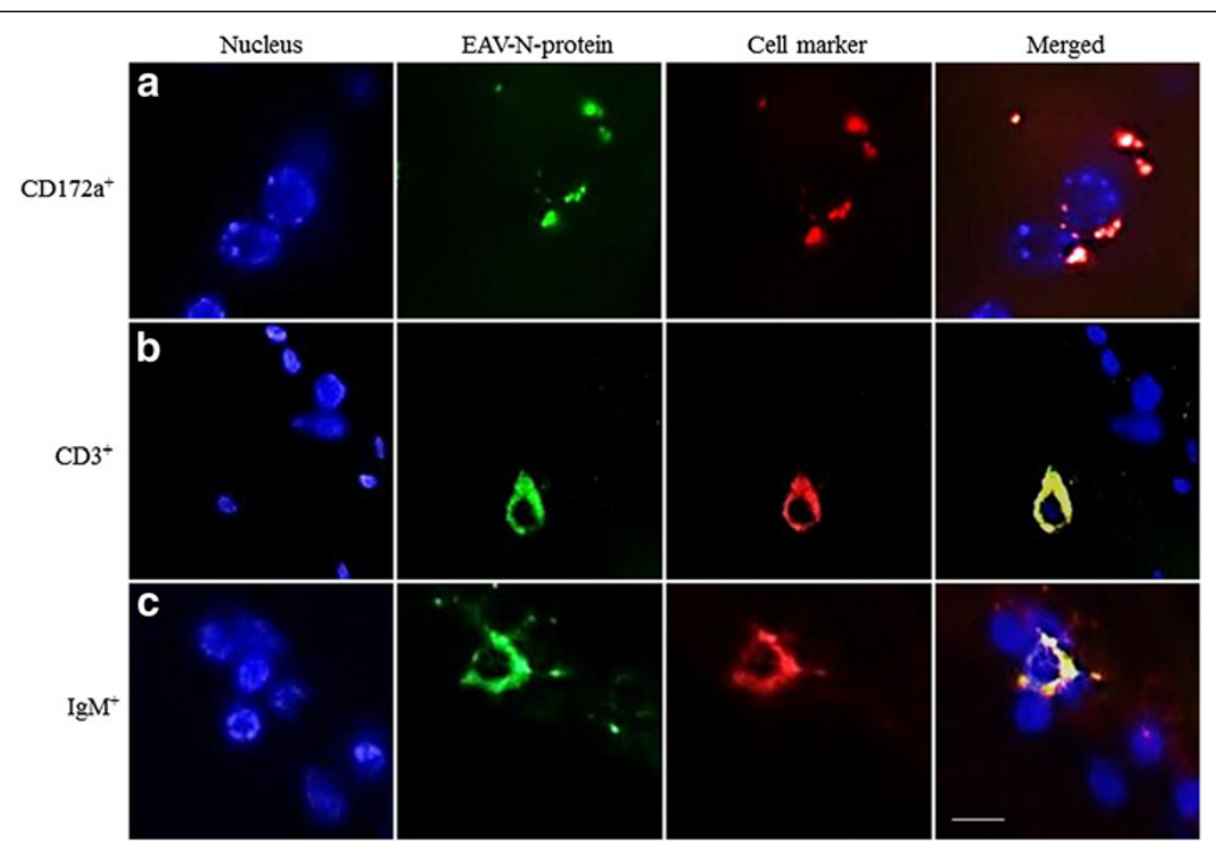

Figure 6 Representative confocal photomicrographs illustrating viral tropism for leukocyte subpopulations. Two different types of EAVpositive cells can be distinguished: big cells with a big round or oval nucleus surrounded by large cytoplasmic extensions mostly CD172a ${ }^{+}$(a) and rather small cells with a big round or oval nucleus surrounded by a small rim of cytoplasm mostly $\mathrm{CD}^{+}$or $\operatorname{lgM}{ }^{+}$(b-c). The viral antigens could be found in the form of small dots (a) or in the form of large masses occupying most of the cytoplasm (b-c). Scale bar represents $10 \mu m$. 
pathogens in the system was restricted to the apical side of the epithelium.

We recently showed that, upon in vivo oro-nasal inoculation, EAV $08 P 178$ starts its replication in nasal and nasopharyngeal regions and lungs [1]. Therefore, to gain more insight into the early phase of EAV respiratory infection, kinetic studies were performed by inoculating the agarose embedded nasal and nasopharyngeal mucosal explants with EAV 08P178. Currently, little is known about the early phases of EAV pathogenesis such as (i) which strategy EAV uses to invade the host, (ii) what are the first cells to be infected at the entry site or (iii) how blood vessels are reached to disseminate the virus throughout the body. The current study showed that in the explant model, the majority of EAV-positive cells were CD172a $\mathrm{a}^{+}$myeloid cells followed by $\mathrm{CD}^{+}{ }^{+}$-lymphocytes, whereas only a small percentage were $\operatorname{IgM}^{+}$B-lymphocytes. Previously, we speculated that, at the level of the URT, EAV hijacks mononuclear leukocytes to penetrate the BM and evade the immune response [1]. In possible support of this, the present study shows a high percentage of EAV-infected CD172a ${ }^{+}$cells. CD172a was expressed on equine monocytes, macrophages, dendritic cells (DC) and granulocytes. DC have specific characteristics: (i) they have a major role in activating naïve and resting antigen-specific T cells [14], (ii) they are migratory cells, unlike differentiated macrophages [15] and (iii) they are abundantly present within the airway epithelium [16] forming a network of antigen presenting cells in the respiratory mucosa $[17,18]$. DC play a central role in initiating an immune response against infecting agents [19] but may also contribute to the pathogenesis and the spreading of several respiratory pathogens as shown for human [20] and simian [21] immunodeficiency viruses, cytomegalovirus [22] and Mycobacterium tuberculosis [23]. Hence, it is tempting to speculate that DC could play an important role in the early phases of EAV pathogenesis. This theory could corroborate the findings of Del Piero that described EAV-antigens within stromal dendrite-like cells of lymph node sinuses and spleen [12]. On the contrary, since the main function of myeloid cells is to capture antigens, $\mathrm{CD} 172 \mathrm{a}^{+}$cells may be positive for the EAV nucleocapsid protein due to phagocytosis rather than infection.

It is generally believed that EAV has a tropism mainly for the monocyte/macrophage population. However, Castillo-Olivares et al. showed that EAV-infected PBMC are negative for the human monocyte/granulocyte marker L1 (calprotectin) [24]. In the present study, both T-lymphocytes and cells of the monocyte/macrophage lineage were found to be infected with EAV. Other studies have also demonstrated that EAV can infect $\mathrm{CD}^{+} \mathrm{T}$ lymphocytes in PBMC in vitro $[25,26]$.

In the present study, 37 to $64 \%$ of EAV-positive cells were identified. Since EAV has a wide tropism [27], the percentage of non-identified EAV-positive cells may be epithelial cells, endothelial cells, mesenchymal stromal cells, and natural killer cells. In fact, in vivo, EAVantigens were demonstrated within the cytoplasm of endothelial cells, myometrial and cardiac myocytes, chorionic mesenchymal stromal cells and epithelial cells such as alveolar pneumocytes, enterocytes, adrenal cortical cells, trophoblast, thymus stroma, and renal tubular cells [27]. Therefore, it will be interesting to further identify the remaining EAV-positive cells in future experiments using the agarose explant system.

Although polarized mucosal explants are much more physiological than non-polarized ones and in vitro cell cultures, they are only suitable to study the early stages of the pathogenesis of viruses that use the respiratory tract as a portal of entry. It must be kept in mind that the mucosal explants not fully represent the whole scope of virus-animal interactions since the inflammatory processes including invasion of blood elements are absent. However, preliminary results obtained with nasal mucosa from experimentally EAV-inoculated ponies were very similar to those of the present in vitro study, confirming the relevance of the polarized mucosal explant system. In conclusion, the present study demonstrates that the agarose embedded explant model represents a valid tool to study some aspects of the early steps in the pathogenesis of equine respiratory viruses such as EAV and that mucosal CD172a $\mathrm{a}^{+}$myeloid cells and $\mathrm{CD}^{+} \mathrm{T}$ lymphocytes represent important target cells for EAV.

\section{Competing interests}

The authors declare that they have no competing interests.

\section{Authors' contributions}

SV set up the study design, carried out the optimization of the organ culture as well as the infection experiments and the processing of all samples, performed the statistical analysis and drafted the manuscript. WVdB participated in the analysis and the interpretation of all the morphological results. HF took part in the analysis and the interpretation of all the immunofluorescence results. AS assisted in the set up of both experiments and sampling. HN coordinated the study and participated in its design. All authors read and approved the final manuscript.

\section{Acknowledgements}

The authors thank M. Bauwens, L. De Bels, L. Standaert and P. De Matteo for technical support. The authors acknowledge M. Pensaert, K. De hert, D. Saha, A. Vandekerckhove, L. Steukers, S. Glorieux, L. Gallina, S. Sivilia, C. Mangano and A. Giuliani for their scientific contribution, helpful suggestions and fruitful discussions. Permission to use the facilities of the department of scienze mediche veterinarie, Faculty of Veterinary Medicine, Alma Mater Studiorum, Bologna University and, in particular, prof. L. Calzà is gratefully acknowledged. S. Vairo is supported by a doctoral grant from the special research fund of Ghent University (V72-0209).

\section{Author details}

'Laboratory of Virology, Department of Virology, Parasitology and Immunology, Faculty of Veterinary Medicine, Ghent University, Merelbeke B-9820, Belgium. ${ }^{2}$ Department of Morphology, Faculty of Veterinary Medicine, Ghent University, Merelbeke B-9820, Belgium. ${ }^{3}$ Laboratory of Immunology, Department of Virology, Parasitology and Immunology, Faculty of Veterinary Medicine, Ghent University, Merelbeke B-9820, Belgium. 
${ }^{4}$ Department of Veterinary Medical Science, Alma Mater Studiorum, Bologna University, Ozzano dell'Emilia, Italy.

Received: 3 November 2012 Accepted: 1 March 2013

Published: 28 March 2013

\section{References}

1. Vairo S, Vandekerckhove A, Steukers L, Glorieux S, Van den Broeck W, Nauwynck H: Clinical and virological outcome of an infection with the Belgian equine arteritis virus strain 08P178. Vet Microbiol 2012, 157:333-344.

2. Glorieux S, Van den Broeck W, van der Meulen K, Van Reeth K, Favoreel H, Nauwynck H: In vitro culture of porcine respiratory nasal mucosa explants for studying the interaction of porcine viruses with the respiratory tract. J Virol Methods 2007, 142:105-112.

3. Vandekerckhove A, Glorieux S, Van den Broeck W, Gryspeerdt A, Van der Meulen $\mathrm{K}$, Nauwynck $\mathrm{H}$ : In vitro culture of equine respiratory mucosa explants. Vet J 2009, 181:280-287.

4. Steukers L, Vandekerckhove A, Van den Broeck W, Glorieux S, Nauwynck H: Comparative analysis of replication characteristics of BoHV-1 subtypes in bovine respiratory and genital mucosa explants: a phylogenetic enlightenment. Vet Res 2011, 42:33.

5. Steukers L, Glorieux S, Vandekerckhove A, Favoreel H, Nauwynck H: Diverse microbial interactions with the basement membrane barrier. Trends Microbiol 2012, 20:147-155.

6. Vandekerckhove A: Equine nasal mucosal explants, a valuable tool to study early events of the pathogenesis of equine herpesvirus infections. In PhD thesis. Merelbeke, Belgium: Gent University, Virology Immunology and Parassitology Department; 2011

7. Araki C: Carbohydrate chemistry of substances of biological interest. In Fourth International Congress of Biochemistry, symposium 1. 1-6 September 1995. Edited by Wolfrom ML. Vienna: Pergamon Press; 1958:1-15.

8. De Maeyer E, Schonne E: Starch gel as an overlay for the plaque assay of animal viruses. Virology 1964, 24:13-18.

9. Hamilton A, Robinson C, Sutcliffe C, Slater J, Maskell J, Davis-Poynter N, Smith K, Waller A: Harrington $1 \mathrm{~J}$ : Mutation of the maturase lipoprotein attenuates the virulence of streptococcus equi to a greater extent than does loss of general lipoprotein lipidation. Infect Immun 2006, 74:6907-6919.

10. Bürki F, Hofer A, Nowotny N: Objective data plead to suspend importbans for seroreactors against equine arteritis virus except for breeder stallions. J Appl Anim Res 1992, 1:31-42.

11. Van Maanen C: Equine herpesvirus 1 and 4 infections: an update. Vet $Q$ 2002, 24:58-78.

12. Del Piero F: Equine viral arteritis. Vet Pathol 2000, 37:287-296.

13. Mumford E, Traub-Dargatz J, Salman M, Collins J, Getzy D, Carman J: Monitoring and detection of acute viral respiratory tract disease in horses. J Am Vet Med Assoc 1998, 213:385-390.

14. Ingulli E, Mondino A, Khotuts A, Jenkins MK: In vivo detection of dendritic cell antigen presentation to CD4T cells. J Exp Med 1997, 185:2133-2141.

15. Lipscomb MF, Masten BJ: Dendritic cells: immune regulators in health and disease. Physiol Rev 2002, 82:97-130.

16. Holt PG, Stumbles PA: Characterization of dendritic cell populations in the respiratory tract. J Aerosol Med 2000, 13:361-367.

17. Holt PG, Schon-Hegard MA, Phillips MJ, McMenamin PG: la-positive dendritic cells form a tightly meshed network within the human airway epithelium. Clin Exp Allergy 1989, 19:597-601.

18. Schon-Hegrad MA, McMenamin OJ, Holt PG: Studies on the density distribution and surface phenotype of intraepithelial class II major histocompatibility complex antigen (la)-bearing dendritic cells (DC) in the conducting airways. J Exp Med 1991, 173:1345-1356

19. Banchereau J, Steinman RM: Dendritic cells and the control of immunity. Nature 1998, 392:245-252.

20. Ayehunie S, Garcia-Zepeda EA, Hoxie JA, Horuk R, Kupper TS, Luster AD, Ruprecht RM: Human immunodeficiency virus-1 entry into purified dendritic cells through CC and CXC chemokine coreceptors. Blood 1997, 90:1379-1386

21. Hu J, Pope M, Brown C, O'Doherty U, Miller CJ: Immunophenotypic characterization of SIV-infected dendritic cells in cervix vagina and draining lymph nodes of rhesus monkeys. Lab Invest 1998, 78:435-451.
22. Hahn G, Jores R, Mocarski ES: Cytomegalovirus remains latent in a common precursor of dendritic and myeloid cells. Proc Natl Acad SCi U S A 1998, 95:3937-3942.

23. Smith J: Mycobacterium tuberculosis pathogenesis and molecular determinants of virulence. Clin Microbiol Rev 2003, 16:463-496.

24. Castillo-Olivares J, Tearle J, Montesso F, Westcott D, Kydd J, Davis-Poynter N, Hannant D: Detection of equine arteritis virus (EAV)-specific cytotoxic $\mathrm{CD}^{+}$T lymphocyte precursors from EAV-infected ponies. J Gen Virol 2003, 84:2745-2753.

25. Go Y, Bailey E, Cook D, Coleman S, Macleod J, Chen K, Timoney P, Balasuriya $\mathrm{U}$ : Genome-wide association study among four horse breeds identifies a common haplotype associated with in vitro $\mathrm{CD}^{+} \mathrm{T}$ cell susceptibility/ resistance to equine arteritis virus infection. J Virol 2011, 85:13174-13184.

26. Go Y, Zhang J, Timoney P, Cook R, Horohov D, Balasuriya U: Complex interactions between the major and minor envelope proteins of equine arteritis virus determine its tropism for equine $\mathrm{CD}^{+} \mathrm{T}$ lymphocytes and CD14 ${ }^{+}$monocytes. J Virol 2010, 84:4898-4911

27. Del Piero F: Equine viral arteritis: signs lesions pathogenesis and diagnoses. In Proceedings of the Annual Meeting of the American College of Veterinary Pathologists and American Society for Veterinary Clinical Pathology: 2-6 December 2006. Edited by IVIS.org. Tucson, Arizona:; 2006.

\section{doi:10.1186/1297-9716-44-22}

Cite this article as: Vairo et al:: Development and use of a polarized equine upper respiratory tract mucosal explant system to study the early phase of pathogenesis of a European strain of equine arteritis virus. Veterinary Research 2013 44:22.

\section{Submit your next manuscript to BioMed Central and take full advantage of:}

- Convenient online submission

- Thorough peer review

- No space constraints or color figure charges

- Immediate publication on acceptance

- Inclusion in PubMed, CAS, Scopus and Google Scholar

- Research which is freely available for redistribution 